\title{
Upaya Meningkatkan Hasil Belajar IPA Melalui Media Pembelajaran Mind Mapping Berbantuan Aplikasi Edraw Mindmaster
}

\section{Wayan Putra Priyandana1*, I Ketut Dibia ${ }^{2}$, Putu Rahayu Ujianti³}

1,2,3 Program Studi Pendidikan Guru Sekolah Dasar, Universitas Pendidikan Ganesha, Singaraja, Indonesia

\section{ART I CLE I N F O}

Article history:

Received March 09, 2021

Revised April 15, 2021

Accepted July 03, 2021

Available online July 25, 2021

\section{Kata Kunci:}

Hasil Belajar, Mind Mapping, IPA

Keywords:

Learning Outcomes, Mind

Mapping, IPA

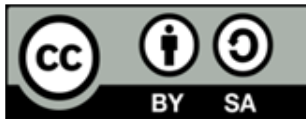

This is an open access article under the CC BY-SA license.

Copyright $(2021$ by Author. Published by Universitas Pendidikan Ganesha.

\begin{abstract}
A B S T R A K
Masih banyak anak yang memiliki kemampuan IPA yang rendah. Hal ini disebabkan karena kurangnya media pembelajaran yang dapat mendukung proses pembelajaran IPA. Penelitian ini bertujuan untuk menciptakan media pembelajaran mind mapping berbantuan aplikasi Edraw Mindmaster. Jenis penelitian ini yaitu penelitian pengembangan dengan menggunakan prosedur 4D. subjek uji coba produk berjumlah 6 orang para ahli. Metode yang digunakan dalam mengumpulkan data yaitu observasi, wawancara, dan kuesioner. Instrument yang digunakan dalam penelitian ini yaitu kuesioner. Teknik analisis data pada penelitian ini yaitu analisis deskriptif kualitatif dan metode analisis deskriptif kuantitatif. Hasil penelitian yaitu penilaian yang dilakukan oleh ahli materi pelajaran mendapatkan nilai 3,75 (sangat baik), hasil penilaian yang dilakukan oleh ahli media pembelajaran mendapatkan nilai 3,41 (sangat baik), dan hasil penilaian dari ahli praktisi mendapatkan nilai 3,76 (sangat baik). Jadi mind mapping memiliki kategori sangat baik sehingga layak diterapkan dalam proses pembelajaran. Implikasi penelitian ini yaitu media yang dikembangkan mind mapping dapat digunakan oleh guru dalam proses pembelajaran, sehingga dapat membantu siswa yang mengalami kesulitan dalam belajar.
\end{abstract}

\section{A BS TRACT}

There are still many children who have low science skills. This is due to the lack of learning media that can support the science learning process. This study aims to develop a mind mapping learning media assisted by the Edraw Mindmaster application. This type of research is development research using $4 D$ procedures. product trial subjects amounted to 6 experts. The methods used in collecting data are observation, interviews, and questionnaires. The instrument used in this research is a questionnaire. Data analysis techniques in this study are descriptive qualitative analysis and quantitative descriptive analysis methods. The results of the research are the assessments made by subject matter experts get a value of 3.75 (very good), the results of the assessments carried out by learning media experts get a value of 3.41 (very good), and the results of the assessments from expert practitioners get a value of 3.76 (very good). It can be concluded that mind mapping has a very good category so that it is feasible to be applied in the learning process. The implication of this research is that the media developed by mind mapping can be used by teachers in the learning process, so that it can help students who have difficulties in learning.

\section{PENDAHULUAN}

Saat ini dunia memasuki era revolusi industri 4.0 sehingga teknologi menjadi sebuah kebutuhan bagi manusia (Lase, 2019; Willya et al, 2019). Berkat kemajuan teknologi semua manusia lebih dimudahkan dalam mengerjakan segala pekerjaan (Harto, 2018; Ridwan et al., 2016). Era revolusi industri ini banyak mempengaruhi segala aspek kehidupan dibidang ekonomi, politik, hingga pendidikan. Salah satu cara untuk dapat bersaing di era ini yaitu manusia harus memiliki kualitas serta keterampilan yang unggul (Shaik Alavudeen et al., 2021; Wulandari et al., 2020). Selain itu kemajuan suatu negara juga tergantung pada sumber daya manusia yang dimiliki. Sehingga untuk mewujudkan manusia yang unggul yaitu diperlukan sebuah pendidikan. Pendidikan memiliki tujuan untuk mengembangkan kemampuan serta membentu watak manusia sehingga menjadi pribadi yang unggul (Siswanto, 2012; Sutrisno, 2016; Widodo, 2015). Dalam mewujudkan tujuan pendidikan nasional maka dikembangkan kurikulum. Pada kulikulum terdapat sepuluh muatan pelajaran, 
salah satunya yaitu ilmu pengetahuan alam (IPA). IPA adalah mata pelajaran wajib (Paramita et al., 2016). Dalam pembelajaran IPA anak akan mampu mengenali makhluk hidup dan alam sekitar (Purnomo \& Wilujeng, 2016; Sari et al., 2019).

Permasalahan yang terjadi saat ini yaitu masih banyak anak yang memiliki kemampuan IPA yang rendah (Resmawan et al., 2017; Yanti, 2016). Hal ini dikarena guru masih menggunakan model pembelajaran tradisional sehingga siswa sulit untuk memahami materi yang disampaikan guru (Agustiani \& Pramita, 2014; Sujana et al., 2018). Selain itu kurangnya media pembelajaran juga berpengaruh pada pemahaman IPA siswa yang kurang (Khofiyah et al., 2019). Berdasarkan hasil observasi dan wawancara yang dilakukan di SD N 3 Terunyan ditemukan permasalahan yaitu masih banyak siswa yang mendapatkan nilai dibawah KKM khususnya pada mata pelajaran IPA. Hal ini disebabkan karena pembelajaran hanya bersifat teacher center. Pembelajaran online hanya mengirimkan materi berupa video yang di download dari youtube dan soal-soal di google class room, dan pembelajaran online kurang memotivasi siswa dalam belajar karena minimnya media pembelajaran yang digunakan. Selain itu guru kurang mampu membuat media inovatif yang memanfaatkan aplikasi terkini. Guru hanya dapat menggunakan sumber belajar yang ada dikelas seperti audio-video.

Solusi yang ditawarkan yaitu penggunaan media pembelajaran yang dapat meningkatkan hasil belajar IPA pada siswa sekolah dasar. Media pembelajaran inovatif akan membantu siswa dalam belajar (Andriyani \& Suniasih, 2021; Gunawan et al., 2017; Putri et al., 2018). Media pembelajaran merupakan perantara yang dapat mengantarkan pesan dari guru ke siswa. Media juga dapat diartikan sebagai alat grafis untuk menangkap, memproses, serta menyusun kembali informasi visual ataupun verbal (Afifah, 2019; Tafonao, 2018; Zulfana et al., 2020). Media ini sebagai sarana komunikasi dan interaksi guru serta siswa dalam pembelajaran. Selain itu, media juga dapat meningkatkan semangat siswa dalam belajar sehingga berdampak pada hasil belajar siswa yang meningkat (Heo \& Toomey, 2020; Khamparia \& Pandey, 2017; Khan \& Masood, 2015). Salah satu media inovatif yang dapat membantu siswa belajar IPA yaitu mind mapping. Mind mapping merupakan media pembelajaran yang membebaskan siswanya untuk menuangkan ide atau konsep sehingga mudah dipahami (Qondias et al., 2016; Sulfemi, 2019). Media ini juga akan membantu daya ingat siswa mengenai materi yang sebelumnya telah dipelajari karena siswa membuat konsepnya sendiri ke dalam mind mapping (Astuti et al., 2013; Sartono et al., 2018). Media ini juga sangat berpotensi membantu siswa dalam memecahkan sebuah masalah serta membuat keputusan mengenai permasalahan tersebut.

Penggunaan media ini juga akna membuat proses pembelajaran menjadi menyenangkan serta mendorong siswa belajar mandiri dan akan berdampak pada prestasi akademiknya yang meningkat (Widiari et al., 2014; Zahro et al., 2018b). Mind mapping yang akan dikembangkan berbantuan aplikasi edraw mind master. Aplikasi Edraw Mindmaster adalah perangkat lunak pemetaan pikiran lintas-platform dan multi-fungsional yang baru saja dirilis oleh Edrawsoft (Mardiah et al., 2019; Sunarman et al., 2015). Alasan pemilihan media mind mapping berbantuan aplikasi Edraw Mindmaster karena pemetaan pikiran yang efektif untuk pemecahan masalah, brainstorming, manajemen pengetahuan, perencanaan bisnis, pembuatan catatan, dan manajemen proyek. Siswa dapat menikmati dari berbagai fitur yang mengesankan termasuk antar muka yang ramah pengguna, opsi tata letak yang melimpah, ikon dan clipart yang sangat bagus, tema preset berkualitas tinggi, impor dan ekspor, dan berbagai macam template. Program ini juga berfokus pada kemampuan kolaborasi seperti penugasan tugas, tampilan Gantt, komentar dan kerja tim cloud.

Temuan penelitian sebelumnya mengenai media mind mapping menyatakan media pembelajaran ini akan membantu siswa dalam belajar (Widiari et al., 2014; Zahro et al., 2018). temuan penelitian lainnya juga menyatakan bahwa media mind mapping memudahkan siswa dalam memahami materi pelajaran sehingga meningkatkan hasil belajar siswa (Liu et al., 2018; Polat \& Aydın, 2020). Kelemahan penelitian sebelumnya yaitu media mind mapping tidak diberikan gambar menarik sehingga kemenarikan media yang dikembangkan kurang. Selain itu belum adanya kajian mengenai media pembelajaran mind mapping berbantuan aplikasi edraw mindmaster yang dapat membantu siswa memahami pembelajaran IPA. Kelebihan media yang akan dikembangkan yaitu media ini berisikan gambar yang sesuai dengan materi pelajaran sehingga memudahkan siswa dalam memahami materi pelajaran. Selain itu terdapat berbagai fitur pada media mind mapping yang dapat meningkatkan semangat siswa dalam belajar. Tujuan penelitian ini yaitu untuk mengembangkan $m$ nd mapping berbantuan aplikasi edraw mindmaster yang dapat membantu siswa memahami pembelajaran IPA. Media pembelajaran ini dapat membantu siswa memahami materi IPA. Diharapkan media ini dapat membantu siswa dalam belajar sehingga dapat meningkatkan hasil belajar siswa.

\section{METODE}

Jenis penelitian ini adalah penelitian pengembangan. Prosedur yang digunakan dalam mengembangkan model ini yaitu model pengembangan 4-D, yang telah termodifikasi yang terdiri dari empat langkah yakni: define, design, develop, dan disseminate. Pemilihan model ini disebabkan karena model ini sangat mudah dipahami dan sistematis. Subjek pada penelitian ini yaitu 2 ahli isi mata pelajaran, 2 ahli media pembelajaran, serta 2 orang ahli praktisi. Teknik yang digunakan untuk mengumpulkan data yaitu observasi, wawancara, dan angket kuesioner. 
Instrument yang digunakan dalam mengumpulkan data yaitu kuesioner. Adapun kisi-kisi instrument pengumpulan data yang digunakan untuk mengetahui validitas produk dapat dilihat pada tabel 1, tabel 2, dan tabel 3. Item-item instrumen yang telah disusun berdasarkan kisi-kisi terlebih dahulu dilakukan uji validitas agar mengetahui kevalidan. Validitas isi digunakan untuk mengetahui ketepatan instrumen dalam suatu variabel yang diukur. Untuk menguji validitas butir-butir instrumen lebih lanjut, maka setelah dikonsultasikan dengan ahli, selanjutnya dianalisis validitas instrumen menggunakan formula Gregory. Teknik uji reliabilitas dalam penelitian ini menggunakan rumus instrumen menggunakan tingkat percentages of agreements antara kedua ahli yang datanya hanya "ya" atau "tidak". Metode dan Teknik analisis data yang digunakan dalam pengembangan media pembelajaran mind mapping berbantuan aplikasi edraw mindmaster yaitu metode analisis deskriptif kualitatif dan metode analisis deskriptif kuantitatif. Metode analisis deskriptif kualitatif dalam penelitian ini untuk menjelaskan mengenai mengolah data berupa masukan, tanggapan, kritik, dan saran dari hasil review para ahli terhadap produk yang dihasilkan. Metode analisis deskriptif kuantitatif digunakan untuk memeroleh rata-rata skor dari masing-masing ahli melalui lembar penilaian.

Tabel 1. Kisi-kisi Kuesioner Ahli Materi

\begin{tabular}{llll}
\hline \multicolumn{1}{c}{ Kategori } & \multicolumn{1}{c}{ Aspek } & \multicolumn{1}{c}{ Indikator } & Nomor Item \\
\hline Ahli Materi & Isi & Kelengkapan, keluasan dan kedalaman & $1,2,3$ \\
& & materi yang disajikan & \\
& Keakuratan & Pengelompokkan teori, prinsip, petunjuk & $4,5,6,7,8$ \\
& Penyajian & Sistematika penyajian, komponen gambar, & $9,10,11,12,13$, \\
& & info-info, kesesuaian gambar dengan & 14,15 \\
& & materi, kesesuaian bahasa yang digunakan \\
\hline
\end{tabular}

Tabel 2. Kisi-kisi Kuesioner Ahli Media

\begin{tabular}{|c|c|c|c|}
\hline Kategori & Aspek & Indikator & Nomor Butir \\
\hline \multirow[t]{5}{*}{$\begin{array}{l}\text { Ahli Desain/ } \\
\text { Media }\end{array}$} & Penyajian komponen & $\begin{array}{l}\text { Sistematika penyajian, penyajian gambar } \\
\text { kesesuaian gambar dan materi }\end{array}$ & $1,2,3$ \\
\hline & Kelengkapan & KI, KD, Pengantar Pembelajaran, Konsep & $4,5,6$ \\
\hline & Komponen & Mind Mapping Berbasis Edraw & \\
\hline & Kelayakan Penyajian & $\begin{array}{l}\text { Bagian pendahuluan, isi dan penutup, desain } \\
\text { cover serta ukuran dan jenis huruf yang } \\
\text { digunakan }\end{array}$ & $7,8,9,10,11$ \\
\hline & $\begin{array}{l}\text { Komponen } \\
\text { penggunaan bahasa }\end{array}$ & $\begin{array}{l}\text { Sesuai dengan perkembangan siswa, } \\
\text { keefektifan kalimat, ketepatan bahasa, dan } \\
\text { konsistensi penggunaan istilah }\end{array}$ & $12,13,14,15$ \\
\hline
\end{tabular}

Tabel 3. Kisi-kisi Kuesioner Ahli Praktisi

\begin{tabular}{llll}
\hline \multicolumn{1}{c}{ Kategori } & \multicolumn{1}{c}{ Aspek } & \multicolumn{1}{c}{ Indikator } & \multicolumn{1}{c}{ Nomor Item } \\
\hline Ahli Praktisi & Materi & $\begin{array}{l}\text { Keluasan, kedalaman dan keakuratan } \\
\text { materi }\end{array}$ & $1,2,3,4,5,6,7$ \\
& Penyajian Komponen & Sistematika penyajian, keterkinian dan & $8,9,10,11$ \\
& Kelengkapan & KI, pengantar, dan konsep & $12,13,14$, \\
& Penyajian & mind mapping berbasis edraw. & 15, \\
& Kelayakan Penyajian & Pendahuluan, Isi, Penutup, rangkuman, dan & $18,19,20,21$, \\
& Komponen & Kesesuaian, keefektifan penggunaan & 22 \\
& Penggunaan Bahasa & kalimat, ketepatan dan konsistensi istilah & \\
& & &
\end{tabular}

\section{HASIL DAN PEMBAHASAN}

\section{Hasil}

Pada penelitian ini dirancang dengan menggunakan model 4D yaitu tahap pendefinisian (define), tahap perancangan (design), tahap pengembangan (development), dan tahap penyebaran (disseminate). Adapun hasil penelitian dari masing-masing tahapan yaitu sebagai berikut. Tahap pertama yaitu pendefinisian (define). Tahap ini dilakukan dengan 4 langkah analisis, yaitu analisis kebutuhan, analisis kurikulum, analisis media, dan analisis 
karakteristik peserta didik. Hasil analisis kebutuhan menunjukkan bahwa perlu adanya sebuah media pembelajaran yang dapat digunakan oleh guru dalam kegiatan pembelajaran di kelas. Hasil analisis kurikulum yaitu kompetensi inti (KI) yang digunakan yaitu memahami pengetahuan faktual, konseptual, prosedural, dan metakognitif pada tingkat dasar dengan cara mengamati, menanya, dan mencoba berdasarkan rasa ingin tahu tentang dirinya, makhluk ciptaan Tuhan dan kegiatannya, serta benda-benda yang dijumpai di rumah, di sekolah, dan tempat bermain. Hasil analisis media yaitu kriteria media yang baik dapat dilihat dari keefektifan, efisiensi, dan komunikatif. Selain memenuhi ketiga syarat tersebut, media yang baik juga harus memenuhi kelima aspek validitas, yaitu: aspek penyajian komponen, aspek kelengkapan komponen, kelayakan penyajian dan komponen penggunaan bahasa. Hasil analsiis karakteristik siswa yaitu bahwa siswa pada tingkat sekolah dasar dinyatakan berada pada tahap operasional.

Tahap kedua yaitu, perancangan (design). Pada tahap ini dilakukan dengan menyusun instrumen penilaian media dan rancang bangun pengembangan media pembelajaran mind mapping berbantuan aplikasi edraw mindmaster. Selain itu pada tahap ini dilakukan kegiatan merancang desain produk. Media yang dirancang merupakan sebuah media pembelajaran mind mapping berbantuan aplikasi edraw mindmaster mengambil materi gaya dan gerak. Media pembelajaran ini diperuntukan kepada siswa kelas IV sekolah dasar. Perangkat lunak yang digunakan dalam pembuatan media adalah Edraw Mindmaster dengan slide 1 halaman. Media pembelajaran tersebut dirancang memiliki ukuran 2,60MB, dengan format pdf. Di dalam mind mapping tersebut akan berisi kotak-kotak kosong yang harus diisi siswa untuk memancing siswa agar dapat berpikir secara terkonsep tentang materi gaya dan gerak. Adapun rancang bangun awal dapat dilihat pada gambar 1 . Tahap ketiga yaitu pengembangan (development). Pelaksanaan tahap pengembangan (development) pada penelitian ini dilakukan dengan mengembangkan produk sesuai dengan rancangan yang telah dibuat. Adapun produk mind mapping yang telah dikembangkan disajikan pada gambar 2 .

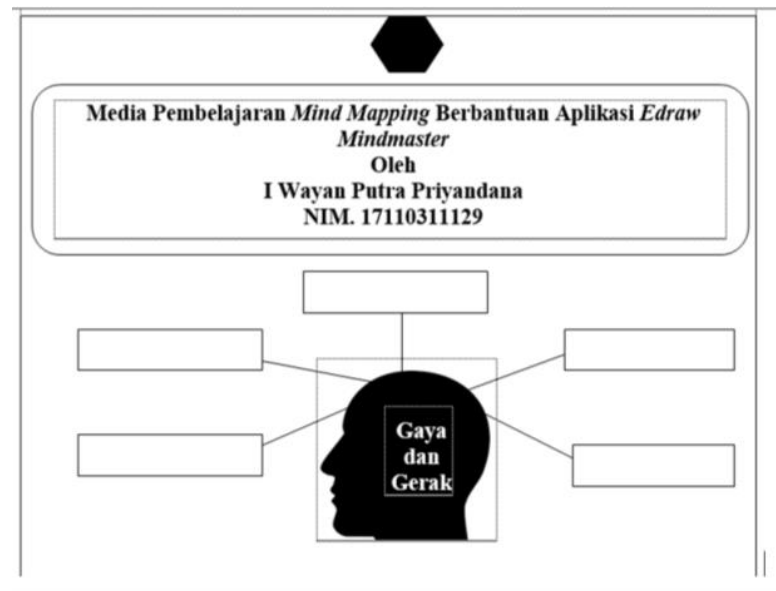

Gambar 1. Rancang Bangun Pengembangan Media

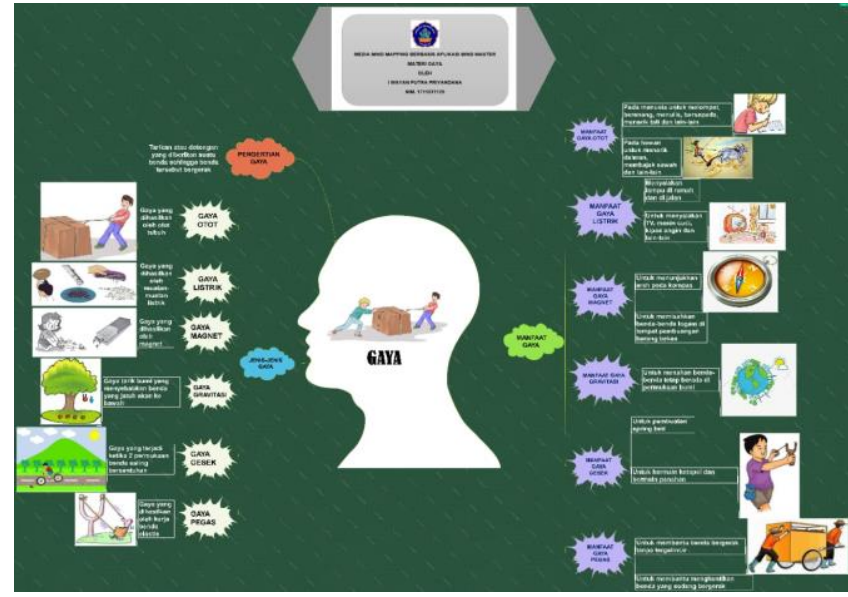

Gambar 2. Media Mind Mapping berbantuan Aplikasi Edraw Mindmaster

Setelah media dikembangkan, maka langkah selanjutnya yaitu penilaian terhadap produk tersebut oleh para ahli dan praktisi guna mengetahui validitas media yang dikembangkan serta memeroleh saran dan komentar, sehingga dapat dilakukan perbaikan terhadap media agar menjadi media yang layak untuk digunakan dalam proses pembelajaran. Data hasil uji validitas media selanjutnya dianalisis untuk mengetahui validitas media yang dikembangkan. Analisis data dilaksanakan dengan menghitung rata-rata skor yang diperoleh dari kedua ahli materi, kedua ahli media, dan kedua praktisi. Selanjutnya, hasil rata-rata skor dikonversikan pada pedoman konversi skala lima untuk mengetahui kualifikasi validitas media pembelajaran mind mapping berbantuan aplikasi edraw mindmaster yang dikembangkan. Berdasarkan penilaian yang diberikan oleh ahli materi pelajaran, media yang dikembangkan yaitu mind mapping berbantuan aplikasi edraw mindmaster yang mendapatkan skor 3,75 sehingga mendapatkan kualifikasi sangat baik. Penilaian yang diberikan oleh ahli media pembelajaran, media yang dikembangkan yaitu mind mapping berbantuan aplikasi edraw mindmaster yang mendapatkan skor 3,41 sehingga mendapatkan kualifikasi sangat baik. Penilaian yang diberikan oleh ahli media pelajaran, media yang dikembangkan yaitu mind mapping berbantuan aplikasi edraw mindmaster yang mendapatkan skor 3,76 sehingga mendapatkan kualifikasi sangat baik. Berdasarkan saran dan komentar yang diberikan oleh ahli materi, dinyatakan bahwa perumusan tujuan pembelajaran pada produk belum sesuai dengan urutan tingkatan capaian kompetensi pengetahuan pada pedoman kata kerja operasional. Adapun saran dan komentar dari para ahli disajikan pada tabel 4. Selanjutnya dilakukan revisan media yang dikembangkan yaitu mind mapping berbantuan aplikasi edraw mindmaster untuk menyempurnakan kekurangan produk. Adapun hasil revisi media disajikan pada gambar 3. 
Tabel 4. Saran dan Komentar Para Ahli

\begin{tabular}{cl}
\hline \multicolumn{1}{c}{ Ahli } & \multicolumn{1}{c}{ Saran dan Komentar } \\
\hline Ahli Materi & 1. Secara umum sudah sangat bagus \\
& 2. Beberapa materi dibuat lebih dalam \\
& 3. Pada sifat-sifat gerak antara gambar dan kolom isi tidak jelas maksudnya \\
& 4. Penampilan gambar tidak proposional \\
Ahli Media 1 & 5. Tulisan dan gambar terlalu kecil \\
& 1. Instrumen sangat sesuai/ relevan \\
& 2. Kekontrasan teks \& latarnya perlu ditingkatkan agar menjadi lebih jelas \\
& 4. Ukuran huruf diperbesar/bold \\
\hline
\end{tabular}

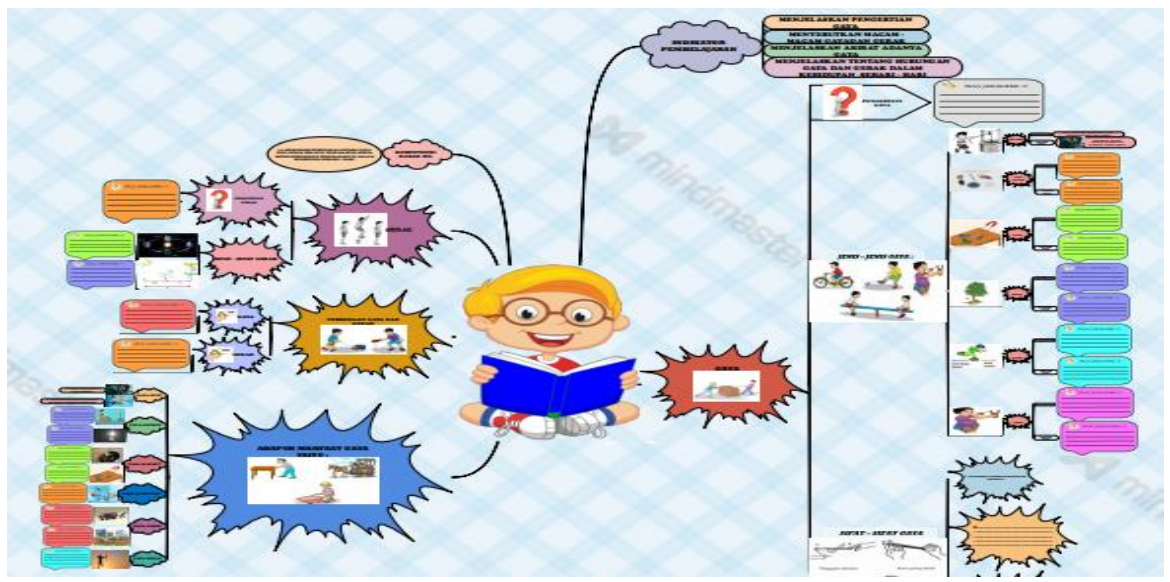

Gambar 3. Hasil Revisi Media Mind Mapping

Berdasarkan hasil analisis data, maka dapat disimpulkan bahwa Media Mind Mapping Berbantuan Aplikasi Edraw Mindmaster mendapatkan kualifikasi sangat baik sehingga layak untuk diterapkan dalam proses pembelajaran. Media Mind Mapping Berbantuan Aplikasi Edraw Mindmaster layak diterapkan dalam proses pembelajaran disebabkan oleh beberapa faktor yaitu sebagai berikut. Pertama, Media Mind Mapping Berbantuan Aplikasi Edraw Mindmaster layak diterapkan dalam proses pembelajaran dapat menarik minat siswa dalam belajar. Media pembelajaran ini dapat memancing siswa mampu membuat peta konsep sendiri tentang materi yang dibelajarkan. Media pembelajarna yang menarik juga dapat meningkatkan semangat serta motivasi siswa dalam belajar (Fu et al., 2019; Liu et al., 2018; Wu \& Chen, 2018). Selain itu, pengembangan Media Mind Mapping berbantuan aplikasi Edraw Mindmaster juga menyajikan gambar yang menarik bagi siswa. Hal ini sesuai dengan temuan penelitian sebelumnya yang menyatakan bahwa gambar yang menarik akan menarik serta memotivasi siswa dalam belajar (Aprinawati, 2017; Dames et al., 2019; Mardati et al., 2015). Media pembelajaran yang dikemas baik akan meningkatkan ketertarikan siswa dalam belajar. media pembelajaran sesunguhnya memiliki peranan yang sangat penting dalam meningkatkan semangat siswa dalam belajar (Handayani \& Abadi, 2020; Umbara et al., 2020). Media pembelajaran ini merupakan salah satu sarana yang dapat digunakan oleh guru jika siswa merasa bosan dalam belajar. oleh karena itu pengembangan media harus kreatif dan semenarik mungkin sehingga anak juga akan merasa tertarik dalam belajar (Devi \& Bayu, 2020; Fauzi et al., 2017; Khofiyah et al., 2019).

Media Mind Mapping Berbantuan Aplikasi Edraw Mindmaster layak diterapkan dalam proses pembelajaran karena memudahkan siswa dalam memahami materi pelajaran IPA. Model pengembangan 4D digunakan karena berpijak pada pendekatan konstruktivisme, sehingga media pembelajaran yang dihasilkan dengan menggunakan model ini dapat membantu siswa dalam membangun pengetahuannya secara mandiri. Pengembangan media yang sesuai dengan karakteristik peserta didik akan memudahkan dalam memahami materi yang disajikan pada media (Gunawan et al., 2017; Sunismi, 2015; Trianawati, 2019). Mind mapping yang dikembangkan membantu siswa dalam memecahkan masalah dan membuat keputusan terkait dengan masalah tersebut. Selain itu, penggunaan Mind mapping akan menyebabkan proses belajar yang menyenangkan dan mendorong anak untuk mandiri belajar serta sukses dalam prestasi akademiknya (Buran \& Filyukov, 2015; Rosciano, 2015). Perencanaan perkembangannya mengikuti sistem kerja otak, bersifat dinamis dengan beragam data visual, variasi tampilan dan pewarnaan (color full) dapat memudahkan siswa dalam memahami materi 
pelajaran (Kiong et al., 2012; Merchie \& Keer, 2016). Jadi, Mind mapping yang dikemas dengan baik akan memudahkan siswa dalam memahami materi pelajaran.

Temuan penelitian sebelumnya juga menyatakan bahwa Mind mapping dapat membantu siswa yang mengalami kesulitan dalam belajar (Bystrova \& Larionova, 2015; López-Bernabé et al., 2020). Temuan penelitian lainnya juga menyatakan bahwa Mind mapping dapat meningkatkan hasil belajar siswa (Abrams \& Byrd, 2016; Pascual et al., 2016). Kelebihan media pembelajaran mind mapping yang dikembangkan yaitu media ini berisikan contoh gambar yang menarik dan sesuai dengan materi pelajaran. Media ini lebih mudah melihat gambaran keseluruhan terkait materi, membantu otak untuk mengatur, mengingat, membandingkan dan membuat hubungan, memudahkan penambahan informasi baru dan Pengkajian ulang dapat dilakukan lebih cepat. Dapat disimpulkan bahwa Mind mapping memudahkan siswa dalam belajar. Implikasi penelitian ini yaitu media yang dikembangkan dapat digunakan oleh guru untuk membantu siswa yang mengalami kesulitan dalam belajar. Selain itu, media Mind mapping juga dapat menjadi fasilitas belajar mandiri siswa. Penggunaan media mind mapping berdampak baik pada peningkatan pemahaman siswa mengenai materi yang dipelajari

\section{SIMPULAN}

Media pembelajaran Mind mapping mendapatkan kategori sangat baik. Media Mind mapping layak diterapkan dalam proses pembelajaran. Media pembelajaran Mind mapping dapat digunakan oleh siswa yang mengalami kesulitan dalam belajar sehingga akan berdampak pada peningkatan hasil belajar siswa khususnya pada pelajaran IPA.

\section{DAFTAR PUSTAKA}

Abrams, Z. I., \& Byrd, D. R. (2016). The effects of pre-task planning on L2 writing: Mind-mapping and chronological sequencing in a 1st-year German class. System, 63. https://doi.org/10.1016/j.system.2016.08.011.

Afifah, N. (2019). Efektivitas Media Ajar untuk Siswa Kelas Rendah Berbasis Nilai Karakter Toleransi terhadap Sesama dengan Berbantu Aplikasi Sparkol Videoscribe. Modeling: Jurnal Program Studi PGMI, 6(2). https://doi.org/10.36835/modeling.v6i2.512.

Agustiani, N. putu I., \& Pramita. (2014). Pengaruh Model Experiential Learning terhadap Keterampilan Berpikir Kritis IPA kelas V Kecamatan Sukasada. Mimbar PGSD Undiksha, 2(1). http://dx.doi.org/10.23887/jjpgsd.v2i1.2609.

Andriyani, N. L., \& Suniasih, N. W. (2021). Development Of Learning Videos Based On Problem-Solving Characteristics of Animals And Their Habitats Contain in Science Subjects On 6th-Grade. Journal of Education, 5(1), 37-47. http://dx.doi.org/10.23887/jet.v5i1.32314.

Aprinawati, I. (2017). Penggunaan Media Gambar Seri Untuk Meningkatkan Kemampuan Berbicara Anak Usia Dini. Jurnal Obsesi : Jurnal Pendidikan Anak Usia Dini, 1(1). https://doi.org/10.31004/obsesi.v1i1.33.

Astuti, N. P. A. W., Ardana, I. K., \& Suardika, I. W. R. (2013). Pengaruh Model Pembelajaran Savi Bermuatan Mind Mapping Terhadap Hasil Belajar IPA Siswa Kelas Iv Sekolah Dasar Gugus III Mengwi. Mimbar PGSD Undiksha, 1(1). http://dx.doi.org/10.23887/jjpgsd.v1i1.1231.

Buran, A., \& Filyukov, A. (2015). Mind Mapping Technique in Language Learning. Procedia - Social and Behavioral Sciences, 206. https://doi.org/10.1016/j.sbspro.2015.10.010.

Bystrova, T., \& Larionova, V. (2015). Use of Virtual Mind Mapping to Effectively Organise the Project Activities of Students at the University. Procedia-Social and Behavioral Sciences, 214. https://doi.org/10.1016/j.sbspro.2015.11.724.

Chaeruman. (2015). Instrumen Evaluasi Media Pembelajaran. Jakarta: Pusat Teknologi Informasi dan Komunikasi Pendidikan Kementrian Pendidikan dan Kebudayaan.

Dames, I., Koeswanti, H. D., \& Radia, E. H. (2019). Penerapan Model Examples Non-Examples Berbantuan Media Gambar Untuk Meningkatkan Hasil Belajar Pada Tema 1 Siswa Kelas 5 SDN Sidorejo Lor 05. Jurnal Basicedu, 3(1). https://doi.org/10.31004/basicedu.v3i2.59.

Devi, P. S., \& Bayu, G. W. (2020). Berpikir Kritis dan Hasil Belajar IPA Melalui Pembelajaran Problem Based Learning Berbantuan Media Visual. MIMBAR PGSD Undiksha, 8(2), 238-252. http://dx.doi.org/10.23887/jjpgsd.v8i2.26525.

Fauzi, H. A., Komalasari, K., \& Malik, Y. (2017). Utilization of Audio-Visual Media to Improve Student Learning Result in IPS Learning. International Journal Pedagogy of Social Studies, 2(1), 88-103. https://doi.org/10.17509/ijposs.v2i1.8666.

Fu, Q.-K., Lin, C.-J., Hwang, G.-J., \& Zhang, L. (2019). Impacts of a mind mapping-based contextual gaming approach on EFL students' writing performance, learning perceptions and generative uses in an English course. Computers \& Education, 137. https://doi.org/10.1016/j.compedu.2019.04.005.

Gunawan, G., Sahidu, H., Harjono, A., \& Suranti, N. M. Y. (2017). The effect of project-based learning with virtual 
media assistance on student's creativity in physics. Jurnal Cakrawala Pendidikan, 1(2). https://doi.org/10.21831/cp.v36i2.13514.

Handayani, R., \& Abadi, I. B. G. S. (2020). Pengaruh Model Pembelajaran Langsung Berbantuan Media Gambar Terhadap Kompetensi Pengetahuan Matematika Siswa Kelas IV SD. Mimbar Ilmu Undiksha, 25(1), 120131. http://dx.doi.org/10.23887/mi.v25i1.24767.

Harto, K. (2018). Tantangan Dosen PTKI Di Era Industri 4.0. Jurnal Pemikiran Dan Penelitian Pendidikan, 16(1). https://doi.org/10.20414/jtq.v16i1.159.

Heo, M., \& Toomey, N. (2020). Learning with multimedia: The effects of gender, type of multimedia learning resources, and spatial ability. Computers and Education, 146, 103747. https://doi.org/10.1016/j.compedu.2019.103747.

Khamparia, A., \& Pandey, B. (2017). Impact of interactive multimedia in E-learning technologies: Role of multimedia in E-learning. Enhancing Academic Research With Knowledge Management Principles, (April), 199-227. https://doi.org/10.4018/978-1-5225-2489-2.ch007.

Khan, F. M. A., \& Masood, M. (2015). The Effectiveness of an Interactive Multimedia Courseware with Cooperative Mastery Approach in Enhancing Higher Order Thinking Skills in Learning Cellular Respiration. Procedia Social and Behavioral Sciences, 176, 977-984. https://doi.org/10.1016/j.sbspro.2015.01.567.

Khofiyah, H. N., Santoso, A., \& Akbar, S. (2019). Pengaruh Model Discovery Learning Berbantuan Media Benda Nyata terhadap Kemampuan Berpikir Kritis dan Pemahaman Konsep IPA. Jurnal Pendidikan: Teori, Penelitian, Dan Pengembangan, 4(1), 61-67. http://dx.doi.org/10.17977/jptpp.v4i1.11857.

Kiong, T. T., Yunos, J. M., Mohammad, B., Othman, W., Heong, Y. M., \& Mohamad, M. M. (2012). The Development and Implementation of Buzan Mind Mapping Module. Procedia - Social and Behavioral Sciences, 64. https://doi.org/10.1016/j.sbspro.2012.11.464.

Lase, D. (2019). Pendidikan di Era Revolusi Industri 4.0. Jurnal Sundermaan, 1(1). https://doi.org/10.36588/sundermann.v1i1.18.

Liu, Y., Tong, Y., \& Yang, Y. (2018). The Application of Mind Mapping into College Computer Programming Teaching. Procedia Computer Science, 129. https://doi.org/10.1016/j.procs.2018.03.047.

López-Bernabé, E., Foudi, S., \& Galarraga, I. (2020). Mind the map? Mapping the academic, citizen and professional stakeholder views on buildings and heating behaviour in Spain. Energy Research \& Social Science, 69. https://doi.org/10.1016/j.erss.2020.101587.

Mardati, Asih, \& Wangit. (2015). Pengembangan Media Permainan Kartu Gambar Dengan Teknik Make A Match Untuk Kelas 1 SD. Jurnal Prima Edukasia, 3(2), 120-132. https://doi.org/10.21831/jpe.v3i2.6532.

Mardiah, M., Hendra, H., \& Hastina, N. (2019). Aplikasi Edraw Mind Map Bagi Guru Sd Negeri 050702 Kecamatan Secanggang Kabupaten Langkat. Jurnal Pengabdian Kepada Masyarakat, 2(2). http://dx.doi.org/10.31604/jpm.v2i2.71-77.

Merchie, E., \& Keer, H. Van. (2016). Mind mapping as a meta-learning strategy: Stimulating pre-adolescents' textlearning strategies and performance? Contemporary Educational Psychology, 46. https://doi.org/10.1016/j.cedpsych.2016.05.005.

Paramita, Tastra, \& Wibawa. (2016). Pengaruh Learning Cycle 5E Terhadap Hasil Belajar IPA Kelas V SD Gugus IV Pupuan. Mimbar PGSD Undiksha, 4(1). http://dx.doi.org/10.23887/jjpgsd.v4i1.6950.

Pascual, M., Miñana, E. P., \& Giacomello, E. (2016). Integrating knowledge on biodiversity and ecosystem services: Mind-mapping and Bayesian Network modelling. Ecosystem Services, 17. https://doi.org/10.1016/j.ecoser.2015.12.004.

Polat, Ö., \& Aydın, E. (2020). The effect of mind mapping on young children's critical thinking skills. Thinking Skills and Creativity, 38. https://doi.org/10.1016/j.tsc.2020.100743.

Purnomo, H., \& Wilujeng, I. (2016). Pengembangan Bahan Ajar dan Instrumen Penilaian IPA Tema Indahnya Negeriku Penyempurnaan Buku Guru dan Siswa Kurikulum 2013. Jurnal Prima Edukasia, 4(1), 67-68. https://doi.org/10.21831/jpe.v4i1.7697.

Putri, Suwatra, \& Tegeh. (2018). Pengaruh Model Pembelajaran PBL Berbantuan Media Gambar Terhadap Hasil Belajar IPA Siswa Kelas III SD. Jurnal Mimbar Ilmu, 23(1), 53-64. http://dx.doi.org/10.23887/mi.v23i1.16407.

Qondias, Anu, \& Niftalia. (2016). Pengembangan Media Pembelajaran Tematik Berbasis Mind Mapping SD Kabupaten Ngada Flores. Jurnal Pendidikan Indonesia, 5(2), 176--182. http://dx.doi.org/10.23887/jpiundiksha.v5i2.8590.

Resmawan, I. K., Pudjawan, K., \& Suarjana, I. M. (2017). Pengaruh Model Time Token Berbasis Tri Hita Karana Terhadap Kompetensi Pengetahuan Ipa Siswa Kelas V. Jurnal PGSD Universitas Pendidikan Ganesha Jurusan PGSD, 5(2), 1-10. http://dx.doi.org/10.23887/jpmu.v1i2.20773.

Ridwan, I., Widiasturi, A., \& Yulianeta, Y. (2016). Pandangan Pramoedya Terhadap Resistansi Perempuan dalam Novel Era Revolusi dan Reformasi. Adabiyyat: Jurnal Bahasa Dan Sastra, 15(1). https://doi.org/10.14421/ajbs.2016.15104. 
Rosciano, A. (2015). The effectiveness of mind mapping as an active learning strategy among associate degree nursing students. Teaching and Learning in Nursing, 10(2). https://doi.org/https://doi.org/10.1016/j.teln.2015.01.003.

Sari, P. E., Koto, I., \& Sakti, I. (2019). Hubungan Kecerdasan Intelektual Dan Hasil Belajar Fisika Siswa Kelas XI IPA SMA. Jurnal Kumparan Fisika, 2(1). https://doi.org/10.33369/jkf.2.1.49-56.

Sartono, N., Komala, R., \& Dumayanti, H. (2018). Pengaruh Penerapan Model Reciprocal Teaching Terintegrasi Mind Mapping Terhadap Pemahaman Konsep Siswa Pada Materi Filum Arthropoda. BIOSFER : Jurnal Pendidikan Biologi, 9(1). https://doi.org/10.21009/biosferjpb.9-1.4.

Shaik Alavudeen, S., Easwaran, V., Iqbal Mir, J., Shahrani, S. M., Ali Aseeri, A., Abdullah Khan, N., ... Abdullah Asiri, A. (2021). The influence of COVID-19 related psychological and demographic variables on the effectiveness of e-learning among health care students in the southern region of Saudi Arabia. Saudi Pharmaceutical Journal. https://doi.org/10.1016/j.jsps.2021.05.009.

Siswanto, B. T. (2012). Model Penyelenggaraan Work-Based Learning Pada Pendidikan Vokasi Diploma III Otomotif. Jurnal Pendidikan Vokasi, 2(1). https://doi.org/10.21831/jpv.v2i1.1013.

Sujana, D. M. A., Dharsana, I. K., \& Jayanta, I. N. L. (2018). Pengaruh Model Pembelajaran Kooperatif Tipe Two Stay Two Stray melalui Lesson Study terhadap Hasil Belajar IPA. MIMBAR PGSD Undiksha, 6(2). http://dx.doi.org/10.23887/jjpgsd.v6i2.19462.

Sulfemi, W. B. (2019). Model Pembelajaran Kooperatif Mind Mapping Berbantu Audio Visual Dalam Meningkatkan Minat, Motivasi Dan Hasil Belajar Ips. Jurnal PIPSI (Jurnal Pendidikan IPS Indonesia), 4(1), 13. https://doi.org/10.26737/jpipsi.v4i1.1204.

Sunarman, I. P. A., Suniasih, N. W., \& Putra, M. (2015). Model Pembelajaran Mind Mapping Berpengaruh Terhadap Hasil Belajar Matematika Siswa Kelas V Sd Gugus 2 Luwus Mekarsari. MIMBAR PGSD Undiksha, 3(1). http://dx.doi.org/10.23887/jjpgsd.v3i1.4841.

Sunismi. (2015). Developing Guided Discovery Learning Materials Using Mathematics Mobile Learning Application As An Alternative Media For The Students Calculus II. Cakrawala Pendidikan, 34(3), 334346. https://doi.org/10.21831/cp.v3i3.7340.

Sutrisno. (2016). Berbagai Pendekatan Dalam Pendidikan Nilai Dan Pendidikan Kewarganegaraan. Jurnal Dimensi Pendidikan Dan Pembelajaran, 4(1). http://dx.doi.org/10.24269/dpp.v4i1.56.

Tafonao, T. (2018). Peranan Media Pembelajaran Dalam Meningkatkan Minat Belajar Mahasiswa. Jurnal Komunikasi Pendidikan, 2(2), 1-13. https://doi.org/10.32585/jkp.v2i2.113.

Trianawati. (2019). Pengaruh Model Discovery Learning Berbantuan Media Animasi Terhadap Kompetensi Pengetahuan IPA Siswa Kelas IV SDN Gugus VI Abiansemal Tahun Ajaran 2018/2019. International Journal of Elementary Education, 4. http://dx.doi.org/10.23887/ijee.v4i1.24337.

Umbara, I. A. A. P., Sujana, I. W., \& Negara, I. G. A. O. (2020). Model Pembelajaran Problem Based Learning Berbantuan Media Gambar Seri BerpengaruhTerhadap Kompetensi Pengetahuan IPS Siswa. Jurnal Mimbar Ilmu, 25(2), 13-25. http://dx.doi.org/10.23887/mi.v25i2.25154.

Widiari, M., Agung, A. A. G., \& Jampel, I. N. (2014). Pengaruh Metode Pembelajaran Mind Mapping dan Ekspositori terhadap Hasil Belajar Matematika di SD Gugus IX Kecamatan Buleleng. Edutech Universitas Pendidikan Ganesha, 2(1). http://dx.doi.org/10.23887/jeu.v2i1.3548.

Widodo, H. (2015). Potret Pendidikan Di Indonesia Dan Kesiapannya Dalam Menghadapi Masyarakat Ekonomi Asia (MEA). Cendekia: Journal of Education and Society, 13(2). https://doi.org/10.21154/cendekia.v13i2.250.

Willya, Poluakan, Dikayuana, Wibowo, \& Raharjo. (2019). Generasi Milenial Pada Era Revolusi Industri 4.0. Focus : Jurnal Pekerjaan Sosial, 2(2). https://doi.org/10.24198/focus.v2i2.26241.

Wu, T.-T., \& Chen, A.-C. (2018). Combining e-books with mind mapping in a reciprocal teaching strategy for a classical Chinese course. Computers \& Education, 116. https://doi.org/10.1016/j.compedu.2017.08.012.

Wulandari, Sudatha, \& Simamora. (2020). Pengembangan Pembelajaran Blended Pada Mata Kuliah Ahara Yoga Semester II di IHDN Denpasar. Jurnal Edutech Undiksha, 8(1), 1-15. http://dx.doi.org/10.23887/jeu.v8i1.26459.

Yanti, K. D. (2016). Pengaruh Model Pembelajaran Kooperarif Tipe Numbered Head Together (NHT) Terhadap Hasil Belajar IPA. MIMBAR PGSD Undiksha, 4(1), 1-10. http://dx.doi.org/10.23887/jjpgsd.v4i1.7445.

Zahro, Degeng, \& Mudiono, A. (2018a). Pengaruh model pembelajaran student team achievement devision (STAD) dan mind mapping terhadap hasil belajar siswa kelas IV sekolah dasar. Educandum: Jurnal Pendidikan Dasar Dan Pembelajaran, 8(2). https://doi.org/10.25273/pe.v8i2.3021.

Zahro, F., Degeng, I. N. S., \& Mudiono, A. (2018b). Pengaruh model pembelajaran student team achievement devision (STAD) dan mind mapping terhadap hasil belajar siswa kelas IV sekolah dasar. Premiere Educandum : Jurnal Pendidikan Dasar Dan Pembelajaran. https://doi.org/10.25273/pe.v8i2.3021.

Zulfana, F., Purwadi, \& Mudzanatun. (2020). Pengaruh Model Nht Berbantu Media Ular Tangga Terhadap Hasil Belajar Siswa Kelas Iv Di Sd N 02 Ujung Pandan Jepara. Elementary School: Jurnal Pendidikan Dan Pembelajaran Ke-SD-An, 7(1). https://doi.org/10.31316/esjurnal.v7i1.474. 